\title{
Entre el clientelismo y el reforzamiento de vínculos familiares: el compadrazgo en las familias indígenas del valle de Melipilla (Chile, 1780-1810)
}

Between Clientelism and Strengthening Family Ties: Compadrazgo in the Indigenous Families of the Melipilla Valley (Chile, I780-I8ro)

DOI: https://10.22380/20274688.844

Recibido: 29 de julio del 2019

Aprobado: 30 de septiembre del 2019
ANDREA MARGARITA ARMIJO REYES**

Universidad de Santiago de Chile andrea.armijo.r@usach.cl

R E S U M E N

Se analizan las relaciones de compadrazgo dentro de la población indígena de los pueblos de indios, que tenían la finalidad de promover estrategias familiares

* $\quad$ El artículo se ha realizado en el marco del Programa Extraordinario "Continuidad de Investigación para Doctores Recientemente Graduados”, Proyecto II 45 USA I799_I_I_3, Relaciones de poder, redes clientelares y estrategias de compadrazgo y apadrinamiento de elites y sectorespopulares. Valle de Melipilla I780-I810. Mis agradecimientos a USA I799 VRIDEI, 031952IG-GO, Universidad de Santiago de Chile.

** Doctora en Historia de la Universidad de Santiago de Chile, docente en el área de Chile y América Colonial en la Universidad de Santiago de Chile. Ha realizado pasantías de investigación en las universidades españolas Autónoma de Madrid y de Murcia; también en la Universidad Federal de Paraná (Brasil). Ha dado a conocer sus investigaciones en congresos nacionales e internacionales (España, Ecuador, Brasil y Argentina) en calidad de ponente y conferencista. En la actualidad tiene adjudicada una beca postdoctoral de la Vicerrectoría de Investigación de la Universidad de Santiago de Chile, encaminada a promover la elaboración de publicaciones con alta indexación a partir del trabajo de pesquisa relacionado con temáticas de compadrazgo, clientelismo y poder. 
encaminadas a formar clientelismo, movilidad social y alianzas de reciprocidad entre padres y padrinos provenientes de lazos familiares consanguíneos, colaterales y de la comunidad, como también con la élite local del valle de Melipilla. La documentación analizada proviene del registro parroquial de la iglesia San José de Melipilla, documentación notarial y registros judiciales, y nos valemos de aquellos mediante la metodología de las redes sociales para analizar los vínculos interpersonales entre distintos sectores y grupos sociales. Los resultados indican que los vínculos de compadrazgo de los indígenas entre pares sociales y élites locales conducen a la búsqueda de favores económicos, como también reafirmación social.

Palabras clave: redes sociales, compadrazgo, clientelismo, familias indígenas, Chile

\section{$\begin{array}{llllllll}\mathbf{A} & \mathbf{B} & \mathbf{S} & \mathbf{T} & \mathbf{R} & \mathbf{A} & \mathbf{C} & \mathbf{T}\end{array}$}

This paper analyzes the relations by compadrazgo of the indigenous population of the indigenous people, with the purpose of promoting family strategies aimed at forming clientelism, social mobility and reciprocity alliances between parents and godparents from consanguineal, collateral and family ties, community as well as with the local elite of the Melipilla Valley. The documentation analyzed comes from the parish registry of the San José de Melipilla church, notarial documentation and judicial records, using those through the methodology of social networks to analyze interpersonal links between different sectors and social groups. The results indicate that the links by indigenous compadrazgo between social peers and local elites lead to the search for economic favors as well as social reaffirmation.

Keywords: social networks, compadrazgo, clientelism, indigenous family, Chile

\section{Introducción}

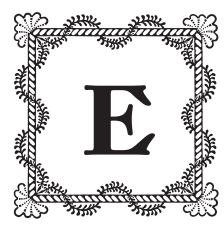

1 bautismo, uno de los principales sacramentos de la Iglesia católica, se inscribe como el primer sacramento de iniciación en la fe cristiana. El Concilio de Trento le otorgó aspectos formales (elección y petición de padrinos), normativos (asistencia a charlas, días en que se puede administrar y quién lo administra) y rituales-simbólicos que culminan en el día de la ceremonia (derramar agua sobre la cabeza, asignar nombre cristiano).

El bautismo significó la formación de un parentesco ritual entre padres, ahijados-ahijadas y padrinos que a su vez promovió estrategias familiares conducentes a formar alianzas de reciprocidad y clientelismo entre padres y padrinos 
provenientes de lazos familiares consanguíneos, colaterales y de la comunidad. En otras palabras, el parentesco espiritual permitió no solo reforzar lazos entre troncos familiares ya emparentados de algún grado, sino también gestar vínculos extradomésticos, fortaleciendo así relaciones de sociabilidad y producción con sujetos del mismo grupo social, como también con las élites locales. De tal modo, se incorporaban nuevas personas a la red de relaciones. Por ello, Gudeman considera que se trata de una práctica flexible porque permite interligar distintos grupos e individuos de la sociedad (22I).

En relación con lo expuesto, deseamos analizar el compadrazgo en función de los posibles intereses y objetivos de las familias indígenas del valle de Melipilla para definir a los padrinos y madrinas hacia fines del siglo XVIII y principios del xIx. Resulta interesante estudiar la importancia del compadrazgo en cuanto práctica social compleja y su incidencia en la construcción de relaciones sociales operadas entre los indígenas, con el objetivo de reconocer las estrategias y los mecanismos de reproducción relacionados con la reciprocidad y la movilidad social que desplegaron, como también la generación de vínculos de solidaridad y clientelismo. En las elecciones de padrinos y madrinas es posible observar niveles de jerarquías y desigualdad social entre padres y compadres, lo que nos lleva a preguntarnos: ¿cuáles sujetos fueron escogidos en reiteradas ocasiones para ser padrinos y madrinas?, ¿cuáles fueron los motivos para escogerlos?, ¿ostentaban fortuna y prestigio social entre sus pares sociales?

Se aborda la sociedad colonial en términos de relaciones y de lo vinculante, donde, según Norbert Elias, los individuos están ligados a otras personas por cadenas invisibles e interdependientes, formando un tejido de relaciones móviles (29). Se trata de una sociedad dinámica que logra establecer relaciones entre los individuos, ya sea desde un plano horizontal en el que existen intereses y lealtades de un mismo grupo social, o desde un plano de interacción de relaciones entre individuos de distinto nivel socioeconómico, actuando a través de la verticalidad. Así, el presente estudio se guía a través del concepto teórico del análisis de red social, una herramienta analítica que permite establecer el comportamiento social y las estrategias de reproducción de la población del valle de Melipilla, útil para entrever la complejidad de las relaciones humanas, tal como enfatizan Guillermina del Valle y Antonio Ibarra: "el análisis de redes como teoría social, sirve para el estudio de la interacción social debido a su gran efectividad como marco interpretativo para explicar el análisis del comportamiento de un sujeto y su sistema de interdependencias sociales" (7). La teoría de las redes sociales presenta potencial porque proporciona información del entorno social, los mecanismos 
utilizados para conseguir apoyos y favores en momentos de dificultad y las estrategias vinculantes. Además, según Requena, se muestra útil ya que tiene en cuenta situaciones de asociación, solidaridad, valores, el poder y el conflicto, junto con los procesos y las estructuras como rasgos de realidad social (I3).

Así, el compadrazgo se inscribe en la perspectiva de las relaciones sociales, que Jesús Contreras abordó en "El compadrazgo y los cambios de estructura de poder local”, en la localidad de Chinchero, Perú, como una institución de implicaciones religioso-morales, económicas y sociopolíticas, destacando que el compadrazgo constituye una estrategia, más o menos consciente, de alianzas en vistas a la consecución de objetivos económicos y políticos (5). También Ángel Montes, en Simbolismo y poder: un estudio antropológico sobre compadrazgo y priostrazgo en una comunidad andina, interpreta el compadrazgo como una estrategia ritual ligada a las relaciones sociales de poder. Así, manifiesta que el compadrazgo es reconocido como una forma de amistad ritualizada que supera, por un lado, la inestabilidad de la amistad, y por otro, la rigidez formal de la familia y, por tanto, concentra la libertad de elección de la amistad y la continuidad ritual del parentesco. Su función principal es la cohesión social y la extensión de los lazos de parentesco (I6I).

Por otra parte, el trabajo de campo etnográfico realizado por Mauricio Chamorro, "Compadrazgo y reciprocidad en los Andes colombianos", se inscribe en los cambios y la permanencia que experimenta el compadrazgo en la actualidad en el municipio de Gualmatán, en el sur de Colombia. El autor define la institución como "una estrategia que permitió sobrellevar el intercambio contractual del mercado a partir de establecer y fortalecer relaciones de producción basadas en la reciprocidad, las que son sustentadas en una obligación moral” (I8).

En este estudio, el compadrazgo se define como un mecanismo que permite la vinculación entre los mismos sujetos de un grupo social, es decir, vinculaciones horizontales, tanto en su dimensión superior (entre sujetos de la élite) e inferior (entre sujetos populares), como también la direccionalidad vertical que une distintas jerarquías en el interior del entramado social. De tal modo, las motivaciones que podían ser realizadas por el compadrazgo tuvieron que ver con los grupos sociales de la población escogidos para emparentarse, con el fin de acceder a recursos materiales e inmateriales que permitieran mejorar o complementar sus estrategias de subsistencia.

El análisis se sustenta en la revisión de las actas de bautismo (4.54I partidas) y las actas de matrimonio (897 partidas) de la parroquia San José de Logroño, resguardadas en el Archivo del Arzobispado de Santiago de Chile. 
Otros documentos bases del estudio fueron los testamentos y las escrituras de compraventa registrados en el Fondo Notarios de Melipilla. Se constataron bienes materiales relacionados con la ganadería y la agricultura (herramientas de labranza), lo que muestra las posibilidades económicas de los padrinos indígenas.

\section{La población del valle de Melipilla}

El contexto rural de la zona central de Chile se revela propicio para observar las relaciones de compadrazgo, padrinazgo y madrinazgo, y nuestro interés se centra en la villa y valle de Melipilla. Este lugar se inscribe geográficamente como estratégico por estar ubicado en un punto intermedio entre la zona de la cordillera de la costa y Santiago, siendo un lugar de paso obligado para los carreteros y mercaderes en su tránsito hacia la capital (Santiago) y los puertos de San Antonio y Valparaíso, que no estuvieron exentos de problemas con las élites locales por los accesos a las carretas, pues se alegaban daños a la propiedad (AHN, CG, vol. 66I, pieza I, el gremio de carreteros de Melipilla contra Josefa Jara por derecho a tránsito, I76I-I762, f. 70) ${ }^{\mathrm{I}}$.Otro aspecto importante del valle fue su capacidad agrícola y ganadera. La existencia de importantes fuentes de regadío (ríos Puangue, Mapocho y Maipo) hizo posible el cultivo de maíz y cebada, así como la producción de trigo. Según Borde y Góngora, las sementeras de trigo se ubicaron en Curacaví, al norte y al sur del río, en Colliguay, San Francisco de Puangue, las tierras de los Allende y el pueblo de indios del Bajo (7I). En relación con la producción y comercialización del trigo, se destacó Alonso Velásquez de Covarrubias, dueño de la hacienda Picó, quien señaló en su inventario de bienes "224 fanegas de trigo colocadas en bodegas del puerto de Valparaíso, otras 600 fanegas de trigo vendidas a 6 reales a fines de la década de I770" (Ahn, NM, vol. IO, I776, f. I6). Por otro lado, en la estancia de Puangue, Juan Balmaceda constató en su inventario del año 1779 una producción de 600 fanegas de trigo (AHN, NM, vol. 4, I779, f. 227 v.). A su vez, en I790 la

I La villa de Melipilla o San José de Logroño fue fundada en 1742 por el gobernador don José Manso de Velasco. La villa fue cabecera del corregimiento y posteriormente partido de Melipilla. Hoy es la provincia de Melipilla, ubicada a la Región Metropolitana de Chile. Los carreteros y mercaderes utilizaron las cuestas de Ibacache y Zapata. 
estancia de Gualemo, de doña Teresa Vicuña, produjo 88 fanegas de trigo blanco (AHN, NM, vol. I4, I790, ff. II7-I32 v.). Por otro lado, la ganadería tuvo gran importancia en el valle de Melipilla, destinada fundamentalmente a la crianza y matanza, con el objeto de beneficiarse de sebo y cueros (cordobanes), como se observa en el inventario de bienes de don Vicente Vargas con una producción de más de 2.500 suelas (AHN, NM, vol. II, I8II).

Por otro lado, el núcleo poblacional de la villa mantuvo chacras, las cuales fueron utilizadas para el cultivo de la vid y la plantación de árboles frutales. Además, pequeños agricultores se relacionan con el arriendo de tierras en los "pueblos de indios" (aHN, CG, vol. I44, I8I6, f. 300).

El valle de Melipilla presenta su particularidad en relación con el entramado social: convergió una élite local y rural asentada desde el siglo xvir, formada por hacendados y estancieros. Hacia fines del siglo xviıI, las familias de la élite local que tuvieron proyección vía linaje fueron los Vargas, Covarrubias, Ugalde, Fuenzalida, Peñalillo, Jara, Calvo y Vicuña, familias asociadas a la posesión de la tierra. Sin embargo, no pueden catalogarse como endogámicas, pues las sucesivas generaciones buscaron mantenerse en el poder mediante la creación de alianzas matrimoniales con otras familias, con lo que le otorgaban un componente de flexibilidad y apertura. De este modo, buscaron relacionarse con familias de la élite de Santiago como los Bascuñan que, por el tipo de actividades económicas del siglo XVIII — la agricultura y el comercio, por excelencia— habían extendido sus negocios por medio de la compra, venta o arriendo de tierras en Melipilla.

Así también, desde la segunda mitad del siglo xviı la villa de Melipilla acogió a inmigrantes peninsulares como los comerciantes Achurra, Piñeiro, Aspillaga y Garaycoechea, que buscaron relacionarse con la élite local mediante el compadrazgo (AAS, $P J M, A B$ 4, I788, 9I v.; $A B$ 5, I793, 217; $A B$ 5, I795, 298). En este contexto, la formación del grupo social de la élite local de Melipilla de fines del siglo Xvin tuvo que ver con un carácter intergeneracional en el que las familias se vieron envueltas en variables coyunturales, generales y particulares, que entraron en juego en momentos en los cuales las familias se encontraban en vías de ascenso y promoción social.

Sin embargo, este entramado social fue más complejo ya que a comienzos del siglo xix había una importante población indígena en el valle de Melipilla, que sobrevivió en los llamados "pueblos de indios" y, a juicio de León, "vivían y se reproducían de acuerdo a patrones arcaicos, en plena autonomía y sin visos 
de desaparecer del horizonte étnico regional” (IOo)². Según el mismo autor, la historiografía nacional ha postulado la desaparición de la población indígena de Chile Central por diversos motivos, entre ellos:

[...] la baja natalidad junto a tierras despobladas y ocupadas por vagabundos mestizos como señaló Gabriel Salazar. Por otro lado, Góngora postuló la invisibilización voluntaria del indio a través del mestizaje y que junto a ello, la asimilación con indios libres para evadir el pago del tributo al rey, se amestiza, huye y deja de vivir como indio en su vestimenta. (99-100)

Además, la población indígena utilizó instituciones legales de la sociedad como el matrimonio, como estrategia para subsistir en los espacios cotidianos. En la villa de Melipilla de un total de 897 actas de matrimonio recopiladas entre I780 y 1816, se obtuvo 69 enlaces matrimoniales entre indígenas; sin embargo, el cuadro relacional fue mucho más variado. La formación de matrimonios mixtos de indígenas pudo crear identidades moldeables en los niños desde edades muy tempranas, influidas por la educación, la cultura, las enseńanzas y los contextos sociales que vivieron los padres, como también las redes personales desarrolladas en la adultez (tabla I).

Los indomestizos quedaron relegados a espacios rurales, específicamente en ámbitos de servicios, comercio, artesanía, hacienda y minería, por lo que el mestizo vivenció procesos de asimilación y exclusión tanto de la cultura española como de la indígena. Sin embargo, en el marco de una sociedad que tendió a la asimilación de la cultura española, el indomestizo adoptó elementos para mimetizarse y asimilarse a los espańoles, como vestimenta, adaptación de oficios urbanos y, como señala Ana María Lorandi, "por el solo hecho de contratarse libremente, con jornales previamente pactados pudieron cambiar su condición fiscal y en algunos casos desprenderse de su adscripción étnica” (II5).

2 Los pueblos de indios nacieron en el siglo XVI a raíz del sistema de encomienda de servicio personal impuesto por la Corona española agrupando a las poblaciones indígenas. Estos eran considerados formas de pequeña propiedad aldeana, que a juicio de Góngora eran mezcla de propiedad individual y comunal, organizados bajo la presión legislativa de la Corona durante el siglo XVII, que intentó crear pueblos de indios alejados de las haciendas con la finalidad de que la etnia indígena desarrollara una vida de acuerdo con sus costumbres, como la organización social y religiosa (Góngora 70). 
$\bullet \quad$ TABLA I

Matrimonios de indígenas con sujetos de distintas calidades étnicas, I780-I8I6

\begin{tabular}{|l|c|l|c|}
\multicolumn{1}{|c|}{ Hombres } & Número de enlaces & \multicolumn{1}{c|}{ Mujeres } & Número de enlaces \\
\hline Indio - española & 2 I & India - español & 9 \\
\hline $\begin{array}{l}\text { Indio - no } \\
\text { especifica }\end{array}$ & I5 & India - mulato & 7 \\
\hline Indio - mulata & 7 & India - pardo & 2 \\
\hline Indio- mestiza & 6 & India - mestizo & I \\
\hline Indio - cuarterona & I & & \\
\hline
\end{tabular}

Fuente: elaboración propia a partir de los registros de matrimonio de la parroquia de San José de Logroño (AAS, AM, libros 2-4, I780-I8I6).

Sin embargo, en el curso medio del río Maipo, es relevante que la población de los pueblos de Melipilla conservara su condición de "india”, la cual le había sido otorgada por la Corona, identificándose como indígenas tributarios del rey (AHn, FCG, vol. 38, pieza 6, Cuenta del subdelegado del partido de Melipilla a la Real Hacienda de los tributos de los pueblos de indios de Melipilla, I794-I798). Algunos no dudaron en defender su condición cuando eran falsamente reconocidos como arrendatarios españoles, como fue el caso de Bernardo Negrete quien se presentó ante el subdelegado Yécora para denunciar que había sido erróneamente notificado por el diputado de El Monte, incitándolo a desalojar la propiedad. Para acreditar su condición de tributario y calidad étnica de indígena y natural del pueblo de Llopeo, dijo ser hijo legítimo de Fermín Negrete, quien fuese hijo de José Santos Negrete

[...] y que siempre han sido tenidos por naturales del pueblo de Llopeo y tributarios, que ha vivido desde tiempo antiguos en el dicho pueblo y gozado de todos los privilegios que a los indios le son concedidos, sin que nadie se los disputase, por ello, pido la restitución del terreno, que por ley me corresponde. (AHN, JM, Sobre que se declare por indio del pueblo de Llopeo, leg. 6, pieza 19, I8I6)

El caso de Negrete ilustra cómo los indígenas continuaron en posesión de sus tierras e identificándose con ellas como destinadas al cultivo de cereales y la crianza de ganado. 
En septiembre de 1785 el fiscal de la Real Audiencia y protector general de los indios don Ramón Martínez de Rozas visitó los pueblos del corregimiento de Melipilla con el objetivo de informar a la superioridad el número de familias, el número de cuadras de tierras y el valor de las tierras de los pueblos de indios de Melipilla, para responder a las primeras diligencias del proyecto de reunirlos en una sola población junto a los pueblos de indios del corregimiento de Santiago (Lampa, Macul, Talagante y Curamapu). La información de los pueblos de indios de Melipilla fue la siguiente: Llopeo con 8 familias y 203 cuadras avaluadas en I.2I8 pesos; Chiñigue con seis familias y I5O cuadras por un valor de venta de 900 pesos; El Bajo con 6 familias y 400 cuadras y la venta de aquellas promedió 2.400 pesos; Pomaire con 24 familias y 300 cuadras y a I.800 pesos la venta de tierras; y Lo Gallardo con 20 familias y 200 cuadras y a I.200 pesos la venta (AHN, CG, vol. 5I2, I785, f. 32).

Los "pueblos de indios" acogieron a población mestiza, españoles pobres y exesclavos africanos que buscaron refugio en aquellas tierras. Por tal motivo, en 1785 Martínez de Rozas consideraba que, por el estado en que se encontraban, los indígenas no merecían el título de pueblos:

[...] son indios nacidos en aquellos lugares o mestizos, mulatos y otras castas que viven allí agregados por gracia de los Caciques o por el arrendamiento que a estos pagan por el uso de las tierras. Yo he encontrado pueblos en que los advenedizos pasaban de 25 y los indios apenas eran 6. (AHN, $C G$, volumen 5I2, 1785, ff. 33-40)

La presencia de foráneos en los pueblos de Melipilla coincide, según León, "con el crecimiento de la plebe santiaguina y el desarrollo de arrabales, junto a la intensificación del tráfico comercial entre Valparaíso y Santiago, favoreciendo un paulatino proceso de migración regional hacia un espacio de relativa autonomía y protegidos por caciques" (IO2).

La población de Melipilla se encontraba dispersa tanto en la villa, en las haciendas, como en los "pueblos de indios", distantes varios kilómetros entre sí, por lo que el trabajo sacerdotal tuvo que ser arduo, considerando los escasos medios de movilización y los caminos en mal estado. A pesar de aquello, la utilización de los registros parroquiales de la primera mitad del siglo XviII por Ema Ojeda y nuestro estudio particular, que abarca la segunda mitad de dicho siglo, muestran que el valle era recorrido casi todos los años en su totalidad por los párrocos y tenientes de párrocos. Así, los recorridos más usuales de los párrocos eran de Melipilla a la costa, Puangue, San Diego, Cuncumén hasta 
llegar a Cartagena, atendiendo en la costa las viceparroquias de san Nicolás, El Rosario, Lo Gallardo, Lo Abarca, San Antonio, Algarrobo, Lagunillas y Peñablanca. Otro recorrido correspondía a la zona norte, recorriendo Lo Soloaga, Mallarauco, Curacaví y Paguilmo. Los meses de invierno recorrían los pueblos de Chiñigue, Pomaire y Llopeo (Ojeda I4).

En el contexto de la sociedad melipillana de fines del siglo xviri, de las 4.939 actas de bautismo registradas en la iglesia San José de Logroño entre I780 y I8ıo, un total de 3.523 niños y niñas bautizados fueron identificados con la calidad étnica de españoles (I.789 hombres y I.734 mujeres), sin especificar la calidad de blanco o blanca. También, predominó la calidad étnica de indio en 740 registros, siendo más hombres ( 388 bautizados) que mujeres ( 352 bautizadas). Por otro lado, 128 bautizados fueron registrados con la calidad de mestizos $(65$ hombres y 63 mujeres).

\section{Los vínculos por compadrazgo de las familias indígenas del valle de Melipilla}

El padrinazgo y el madrinazgo simbolizan el lugar del padre y de la madre, quienes protegen, cuidan, educan y gobiernan al ahijado o ahijada, que asume una posición de obediencia y fidelidad hacia los "padres espirituales". En el caso del compadrazgo, también se observa una diferenciación jerárquica y casos de desigualdad social que se evidencian en el momento en que los padres escogen a los padrinos (compadres-comadres). Esta era una diferencia que a simple vista no presentaba mayores implicaciones sociales, pero si se considera que algunos compadres y comadres eran más escogidos que otros u otras, es posible advertir la diferencia de prestigio entre ellos o ellas. En este sentido, Eliane Cristina Lopes sostiene: "escoger un padrino o madrina envolvía un hecho básico, que era pedir el favor de apadrinar un hijo o pariente, en cuanto ser escogido significaba conceder un favor" (190). Dicha afirmación se puede expresar de la siguiente forma, escoger/pedir - ser escogido/dar; por consiguiente, quien pide precisa más de quien da. El o la que pide, está siempre en una situación inferior que quien da.

Esta representación simbólica de la diferencia se hacía más visible cuando relucían elementos concretos como la situación socioeconómica o el capital político-social de los compadres junto con el prestigio ostentado en la sociedad. De esta manera, destacaban más algunos compadres, como eran los hacendados 
o comerciantes. Sin embargo, sujetos populares también fueron elegidos en reiteradas ocasiones para ser padrinos o madrinas por sus pares sociales. En tal contexto, definimos el prestigio como

[...] aquel instrumento de poder concedido a una persona o personas por las comunidades en que actúa y que se determina por la influencia, ascendiente, autoridad o dominio moral que goza aquel que lo posee frente a los demás individuos que se relacionan con él. (De Ramón 195-196)

Los casos presentados en la tabla 2 registran a padrinos y madrinas indígenas que en conjunto fueron buscados en reiteradas ocasiones y constituyeron parejas matrimoniales fuertes en el establecimiento de padrinazgos y madrinazgos en la villa de Melipilla.

\section{$\rightarrow$ TABLA 2}

Padrinazgos y madrinazgos indígenas escogidos en reiteradas ocasiones, I780-I810

\begin{tabular}{|c|c|c|c|c|}
\hline Esposo & $\begin{array}{l}\text { Número de } \\
\text { ahijados }\end{array}$ & Esposa & $\begin{array}{l}\text { Número de } \\
\text { ahijados }\end{array}$ & $\begin{array}{c}\text { Número de } \\
\text { apadrinamientos } \\
\text { juntos }\end{array}$ \\
\hline Juan Mesa & $\begin{array}{c}18 \\
(1782-1806)\end{array}$ & $\begin{array}{l}\text { Ignacia } \\
\text { Caritoro }\end{array}$ & $\begin{array}{c}8 \\
(1786-1805)\end{array}$ & 4 \\
\hline José María Balcázar & $\begin{array}{c}12 \\
(1785-1810)\end{array}$ & $\begin{array}{l}\text { Manuela } \\
\text { Calderón }\end{array}$ & $\begin{array}{c}23 \\
(1780-1810)\end{array}$ & 7 \\
\hline Toribio Calderón & $\begin{array}{c}9 \\
(1795-1810)\end{array}$ & $\begin{array}{l}\text { María del } \\
\text { Carmen Ulloa }\end{array}$ & $\begin{array}{c}16 \\
(1788-1810)\end{array}$ & 6 \\
\hline Gregorio Ahumada & $\begin{array}{c}8 \\
(\mathrm{I} 788-\mathrm{I} 805)\end{array}$ & $\begin{array}{l}\text { Dolores } \\
\text { Carbajal }\end{array}$ & $\begin{array}{c}7 \\
(\mathrm{I} 790-\mathrm{I} 804)\end{array}$ & 4 \\
\hline Rosauro Canileu & $\begin{array}{c}7 \\
(\mathrm{I} 790-\mathrm{I} 8 \mathrm{IO})\end{array}$ & Josefa Herrera & $\begin{array}{c}\mathrm{I} 4 \\
(\mathrm{I} 792-\mathrm{I} 8 \mathrm{IO})\end{array}$ & 3 \\
\hline Cayetano Carrera & $\begin{array}{c}6 \\
(1789-1806)\end{array}$ & Basilia Carrasco & $\begin{array}{c}7 \\
(178 \mathrm{I}-\mathrm{I} 806)\end{array}$ & 3 \\
\hline $\begin{array}{l}\text { Don Tomás Soriano } \\
\text { Cacique }\end{array}$ & $\begin{array}{c}5 \\
(1789-179 I)\end{array}$ & $\begin{array}{l}\text { Pascuala } \\
\text { Escobar }\end{array}$ & $\begin{array}{c}10 \\
(1780-1799)\end{array}$ & 4 \\
\hline
\end{tabular}

Fuente: elaboración propia a partir de los registros de bautismo de la parroquia de San José de Logroño (AAS, AB, libros 4-7, I780-I8IO). 
Los casos presentados resaltan que el parentesco espiritual fue un importante mecanismo de dinamización de las comunidades rurales pobres. La incidencia de optar por compadres y comadres de condición popular hace pensar en la preferencia de los sujetos por establecer vínculos horizontales de compadrazgo, lo que pudo reforzar lazos de parentesco ya existentes, pero también ser indicio de que los individuos estuvieran situados en un lugar superior, respaldados por recursos económicos importantes, y de ahí cosechar un prestigio dentro de sus pares sociales. También, la ampliación de los lazos familiares a través del apadrinamiento pudo significar tener personas con quien contar, aunque no fuese económicamente, sino más bien como aliados o parientes. Sin duda, como señala Cristiano Lima da Silva, "las elecciones son resultado de determinadas informaciones, influencias, consejos, presiones y expectativas futuras” (5). Ahora bien, ¿cuál pudo ser la situación económica y social de los compadres de las familias populares?

En la documentación consultada, a pesar de las restricciones en cuanto a registrar las vivencias y experiencias de los indígenas, se encuentran padrinos que detentaron patrimonios materiales importantes. Fue el caso de Juan Mesa (I8 apadrinamientos 1782-1806), quien poseyó algunos bienes de importancia como señala la partición de sus bienes realizada en I8Ir. Este documento refiere que ni Mesa ni su esposa, Ignacia Caritoro, aportaron bienes al matrimonio, que todo se adquirió durante la vida de casados, y dejaron constancia de ello en unos apuntes para su hijo Juan José, su albacea. Dichos bienes en su mayoría habían sido vendidos en i8II y dejados en herencia a los hijos:

IOO pesos de una chacarilla vendida en I8II; un sitio en 50 pesos, una carreta vieja vendida en Io pesos, una yunta de bueyes que se vendió en I2 pesos, herramientas como asuela y gurbia, carretera vendida en I peso, una yegua vendida en I peso, dos yugos vendidos en I peso, más 30 pesos que era la legítima para Nicolás y 30 pesos para Luisa. A la hija Isidora se le dio vestuario en 30 pesos, y a Francisco se le dieron dos caballos tasados en 16 pesos, y a Antonia también 30 pesos, a Santiago se le dieron Ioo pesos en la carreta, dos yuntas de bueyes, espuelas de plata y freno. A la hija Rafaela se le dio una mesa grande con cajón tasada en 6 pesos, importando todos los bienes 450 pesos, rebajándose de ese caudal algunas deudas como la tasación del sitio y los honorarios del tasador y la escritura de venta de la chacarilla, quedando en total 435 pesos y de caudal partible entre el dicho Juan Mesa y su primera mujer correspondió 217 pesos para cada uno. (AHN, NM, vol. 26, Melipilla, 4 de mayo de I8II, ff. I-8) 
El caso de Juan Mesa ilustra una vida material más estable, ligada al trabajo de la tierra y quizás con perspectiva de sobrevivencia más amplia, en relación con aquellas familias que aún no habían logrado un buen pasar, lo que pudo significar que las familias populares buscaran compadres que pudiesen contribuir en la educación o apoyo material en el futuro de sus ahijados.

La sociedad rural de Melipilla de fines del siglo xvin y comienzos del XIX se mostró compleja a partir de las relaciones sociales que la comunidad estableció, un complejo de telas invisibles en el que fue importante la relación de proximidad, solidaridad y afectividad que mediaba entre las personas para escoger a un determinado padrino o madrina de bautizo. Por otra parte, también fue importante la funcionalidad del lazo del compadrazgo, pues los padrinos podían entrar a resolver cuestiones determinantes para las familias como, por ejemplo, la subsistencia económica.

Los vínculos económicos y sociales reforzados por el compadrazgo se dejaron sentir en el pueblo de indios de Llopeo del partido de Melipilla, en el que las redes económicas y sociales fueron defendidas por el cacique Mauricio Saravia cuando las autoridades estimaron sacar a los arrendatarios españoles/ mestizos del pueblo en junio de I8I6. El subdelegado Yecora observó que los arrendatarios estaban perjudicando a los indígenas por dejar a estos sin tierras suficientes para la crianza del ganado y el cultivo agrícola. Sin embargo, el cacique Saravia expuso a las autoridades situaciones de ayuda y auxilio que consentían los mismos arrendatarios. Así, resaltó que los indígenas de Llopeo "han acogido en sus pertenencias por propia comodidad y conveniencia a varios españoles, con quienes viven y de quienes reciben auxilio ya en sus sembrados, y ya en los trabajos de que se fomentan" (AHN, cg, Expediente promovido por el cacique Mauricio Saravia por si y por varios naturales sobre que se les permita vivir en compañia de aquellos españoles de su satisfacción, vol. I44, I816, f. 300).

El cacique Saravia especificaba que la orden emanada solo conllevaría graves perjuicios a las relaciones económicas que habían asociado a los sujetos del pueblo. Así, por ejemplo, "unos pierden el amparo, otros a los sujetos con quienes tienen sus relaciones para la labor, y otros finalmente el corto provento de sus tierras que no pueden beneficiar, o por su inercia o capacidad natural" (AHN, $C G$, vol. I44, I8I6, f. 300).

La apreciación del cacique de Llopeo por los arrendatarios y habitantes no indígenas en sus tierras recayó en la importancia de las redes sostenidas por la comunidad en su conjunto, en la cual esos lazos económicos se mantuvieron, fortalecieron y reforzaron por el compadrazgo. Así, por ejemplo, Pedro Tello, 
arrendatario de las tierras de Mauricio Saravia, junto a su esposa María González buscó como madrina de bautizo de su hijo Ramón Tello a María Peña, también arrendataria del cacique de Llopeo, y por padrino a Francisco Vásquez, en abril de 1803 (aAs, libro 6, Acta de bautismo Ramón Tello, AB, I803, f. 25). Es decir, la comunidad escogió a campesinos-agricultores/ganaderos como compadres y padrinos, a quienes permitió generar un vínculo de trabajo que en el futuro les pudiera reportar beneficios, como la ocupación de la mano de obra en la producción agrícola o ganadera de sus compadres.

También se debe considerar que el resultado esperado con el compadrazgo no siempre pudo alcanzarse, ya fuera por rupturas de las alianzas, conflictos, divergencias y distanciamientos entre los compadres, o por la merma de la economía familiar de los padrinos y madrinas. Así, el vínculo espiritual por sí solo no garantizaba que la reciprocidad de intereses fuera a concretarse en el tiempo.

Si se continúa con el análisis del compadrazgo en la direccionalidad horizontal, destacan las relaciones que establecieron los indígenas con los caciques de los pueblos, que se tornaron en relaciones clientelares por el estatus y poder que tenían las autoridades cacicales.

En la perspectiva de los vínculos, es significativo el estudio de Imolesi, pues investigó el parentesco ritual en los poblados de Sacasa y Acasio ubicados al norte de Potosí, entre i655 y I782. La autora observó que en el periodo I666-I683 la tendencia fue que los padrinos provinieran de familias cacicales locales. Sin embargo, desde mediados del siglo xviıI, el número de padrinos de la nobleza indígena local disminuyó. Respecto a los cambios en las elecciones de padrinos, Imolesi sostiene que el padrinazgo habría permitido a los caciques locales posicionarse como detentadores de un poder simbólico conferido por la autoridad colonial. En alianza con ella,

[...] esta condición de padrinos espirituales que adquirieron los mallkus sobre el conjunto de la población, aunque se fue diluyendo con el transcurso del periodo colonial según muestran las fuentes, cumplió sin embargo el rol inicial, necesario y a la vez sumamente ambiguo de convertirlos en intermediarios entre su gente y el cristianismo que había llegado para quedarse. (Imolesi I2)

La tabla 3 destaca a padres que decidieron multiplicar sus estrategias para asegurar la reproducción social y seguir reforzando los lazos dentro de la comunidad. Así, aseguraban el mecanismo de la reciprocidad y de los intercambios, por lo que la elección del padrino cacique y su parentela se hacía importante. 
$\rightarrow$ TABLA 3

Compadrazgos del cacique del pueblo de Chiñigue Domingo Tello y su esposa Mariana González, I783-1802

\begin{tabular}{|c|c|c|c|c|}
\hline $\begin{array}{l}\text { Año del } \\
\text { bautizo }\end{array}$ & $\begin{array}{c}\text { Nombre y } \\
\text { calidad étnica } \\
\text { del bautizado }\end{array}$ & Padres & Padrino & Madrina \\
\hline 1783 & $\begin{array}{l}\text { José Urbano } \\
\text { Zúñiga } \\
\text { Español }\end{array}$ & $\begin{array}{l}\text { Asencio Zúñiga } \\
\text { Josefa González }\end{array}$ & Domingo Tello & Micaela González \\
\hline 1783 & $\begin{array}{l}\text { Ventura Donoso } \\
\text { Española }\end{array}$ & $\begin{array}{l}\text { Pascual Donoso } \\
\text { Pascuala }\end{array}$ & $\begin{array}{l}\text { Domingo Tello } \\
\text { Silverio Donoso }\end{array}$ & $\begin{array}{l}\text { María Espina } \\
\text { P. Silva }\end{array}$ \\
\hline 1785 & $\begin{array}{l}\text { Santos } \\
\text { Mestizo }\end{array}$ & $\begin{array}{l}\text { Padres no } \\
\text { conocidos }\end{array}$ & $\begin{array}{l}\text { Domingo Tello } \\
\text { José Quiroz }\end{array}$ & $\begin{array}{l}\text { Paula Hernández } \\
\text { Petronila Tello }\end{array}$ \\
\hline 1785 & $\begin{array}{l}\text { Santiago } \\
\text { Indio }\end{array}$ & $\begin{array}{l}\text { Padres no } \\
\text { conocidos }\end{array}$ & $\begin{array}{l}\text { Domingo Tello } \\
\text { José Díaz }\end{array}$ & $\begin{array}{l}\text { Paula Hernández } \\
\text { Petronila Paje }\end{array}$ \\
\hline 1787 & $\begin{array}{l}\text { José Francisco } \\
\text { Piturra } \\
\text { Indio }\end{array}$ & $\begin{array}{l}\text { Agustín Piturra } \\
\text { María Tello }\end{array}$ & Domingo Tello & $\begin{array}{l}\text { Mariana } \\
\text { González }\end{array}$ \\
\hline 1795 & $\begin{array}{l}\text { Antonio Núñez } \\
\text { Español }\end{array}$ & María Núñez & $\begin{array}{l}\text { Domingo Tello } \\
\text { Bacilio Cárdenas }\end{array}$ & $\begin{array}{l}\text { Mariana } \\
\text { González } \\
\text { Josefa Paje }\end{array}$ \\
\hline 1802 & $\begin{array}{l}\text { María del } \\
\text { Carmen Paje } \\
\text { India }\end{array}$ & $\begin{array}{l}\text { Antonio Paje } \\
\text { María de los } \\
\text { Santos Ahumada }\end{array}$ & $\begin{array}{l}\text { Domingo Tello } \\
\text { Romualdo Aros }\end{array}$ & $\begin{array}{l}\text { Salvadora Paje } \\
\text { María Núñez }\end{array}$ \\
\hline
\end{tabular}

Fuente: elaboración propia a partir de los registros de bautismo de la parroquia de San José de Logroño y capilla de Chiñigue (AAS, libros 4, 5 y 6, I783-1802).

Las relaciones de compadrazgo establecidas por el cacique de Chiñigue Domingo Tello eran importantes también para él, ya que acrecentaban las posibilidades de tener mayor reconocimiento dentro de la comunidad del pueblo, considerando que las relaciones se forman en torno al reconocimiento de los otros. A su vez, los compadres del cacique creaban un lazo más firme con la autoridad del pueblo, pero también, por estar emparentados con la principal autoridad, cabe la posibilidad de que su compromiso con la comunidad fuese mayor cuando sus presencias fueran requeridas para servir. En virtud de ello, debían corresponder de buena manera a ese llamado. En tal sentido, el cacique 
ponía a disposición de la comunidad su red de relaciones inmediatas, acrecentando así su prestigio y derecho sobre esta cuando él la requiriera. Por el contrario, la figura del cacique se presenta como intermediario social, ya que podía relacionarse con las autoridades hispanas directamente y establecer consensos, hacer peticiones u obtener beneficios para alguno de sus compadres o comadres que necesitaran de algún tipo de ayuda judicial. De tal modo, la figura del compadre-cacique resalta en importancia, por las redes que lo envolvían, y podía ser beneficioso para sus compadres.

De acuerdo con la idea anterior, para los caciques sería muy significativo el reconocimiento de autoridad otorgado por los miembros del pueblo mediante la petición para formar parentesco por compadrazgo, como se advierte en el número de enlaces del cacique del pueblo de Pomaire, Tomás Soriano, y su esposa Pascuala Escobar (tabla 4).

$\rightarrow$ TABLA 4

Compadrazgos del cacique del pueblo de Pomaire Tomás Soriano, I789-I79I

\begin{tabular}{|c|c|c|c|c|}
\hline $\begin{array}{l}\text { Año del } \\
\text { bautizo }\end{array}$ & Nombre & Padres & Padrino & Madrina \\
\hline 1789 & $\begin{array}{l}\text { Clara Rodríguez } \\
\text { Española }\end{array}$ & $\begin{array}{l}\text { Luis Rodríguez } \\
\text { Teresa Cárdenas }\end{array}$ & Tomás Soriano & Pascuala Escobar \\
\hline 1790 & $\begin{array}{l}\text { Rafael } \\
\text { Español }\end{array}$ & $\begin{array}{l}\text { Francisca } \\
\text { Meneses }\end{array}$ & $\begin{array}{l}\text { Tomás Soriano } \\
\text { Julián Torres }\end{array}$ & $\begin{array}{l}\text { Simona } \\
\text { Roa María } \\
\text { Maldonado }\end{array}$ \\
\hline 1790 & $\begin{array}{l}\text { Tomás } \\
\text { Español }\end{array}$ & $\begin{array}{l}\text { José Zúñiga } \\
\text { Prudencia } \\
\text { Arriagada }\end{array}$ & Tomás Soriano & Pascuala Escobar \\
\hline I79I & $\begin{array}{l}\text { José Isidro } \\
\text { Mulato }\end{array}$ & $\begin{array}{l}\text { Cruz Ifran } \\
\text { Josefa Duran }\end{array}$ & Tomás Soriano & Pascuala Escobar \\
\hline I79I & $\begin{array}{l}\text { Miguel } \\
\text { Mulato }\end{array}$ & $\begin{array}{l}\text { Miguel Cisternas } \\
\text { Ventura Barros }\end{array}$ & Tomás Soriano & Pascuala Escobar \\
\hline
\end{tabular}

Fuente: elaboración propia a partir de los registros de bautismo de la parroquia de San José de Logroño (AAS, AB, libro 5, ff. I34, I58, I64, I77 V., 200, I789-I79I).

El reconocimiento de la autoridad por compadrazgo fue importante en circunstancias en las cuales los caciques buscaron la legitimidad de su poder y 
en contextos que asumían los cacicazgos de forma estrepitosa. Precisamente, los indígenas del pueblo de Pomaire no se sentían conformes con Tomas Soriano, ya que su cargo de cacique había sido impuesto por la familia de hacendados Covarrubias en 177I, mediando el defensor de Covarrubias, quien pidió a la Real Audiencia que reconociera como cacique a Soriano. Aquella imposición había desembocado en conflictos con algunos indígenas del pueblo de Pomaire, como Mariano Hernández, quien había rehusado obediencia a Soriano, no había pagado los tributos y era acusado de conspirar y aconsejar a los demás indígenas que se alzasen en contra de su cacicazgo y reconocieran como cacique a Luis Mesa (AHN, RA, Autos que sigue el Protector General de Indios contra Diego Velásquez de Covarrubias encomendero del pueblo de Pomaire, por malos tratamientos dados a los indios de su encomienda, vol. 219I, pieza 7, I77I, f. 235).

De tal forma, las peticiones de las familias del pueblo de Pomaire para que Soriano fuese su compadre constituyeron una manifestación de apoyo y fortalecimiento de su poder en la comunidad, lo que podía reportar beneficios futuros, como los vínculos sociales de Soriano con la familia Covarrubias quien podía interceder en futuros litigios.

Otro caso importante ocurrió en 1826 cuando el cacique Javier Guentepalma del pueblo de El Bajo fue despojado del cacicazgo por el gobernador de Melipilla don Manuel Valdés y reemplazado por el juez celador Anselmo Romo, por motivos que los indígenas del pueblo atribuyeron a rivalidades entre el exgobernador Valdés y el cacique. Los indígenas del pueblo exigieron al nuevo gobernador Julián de Yécora restituir en el cargo a Guentepalma, manifestando que el despojo era violencia contra el cacique. Los indígenas exigieron la presencia del cacique, a quien consideraban un padre, y manifestaron: "se requiere a su empleo al dicho cacique don Javier Guentepalma, que por derecho lo tiene dicho cargo, quien en cumplimiento de su obligación y como padre de nosotros, remediara a beneficio de los naturales los daños y perjuicios" (aHN, JM, Sobre reposición del cacicazgo a Gabriel Guentepalma, leg. 4, pieza 8, Melipilla I826, f. 2). Así, se observa la ayuda y el apoyo reportados por los indígenas hacia su cacique, que se presenta como una figura central y relevante en la conducción política, social y económica del pueblo.

La visión de padre proyectada en el cacique se relaciona con los compadrazgos establecidos por el cacique Carlos Tello. Este fue pedido como padrino de bautismo por cuatro madres solteras, lo que podría reflejar vínculos de cercanía, confianza y lealtad, además, y relacionado con que las madres debieron 
criar solas a los niños, aquellas pudieron proyectar en el padrino-compadre y cacique-padre un vínculo de ayuda y beneficios futuros para los hijos (tabla 5).

or TABLA 5

Compadrazgos del cacique Carlos Tello, I784-1802

\begin{tabular}{|c|l|l|l|l|}
\hline $\begin{array}{c}\text { Año del } \\
\text { bautizo }\end{array}$ & \multicolumn{1}{|c|}{ Nombre } & \multicolumn{1}{|c|}{ Padres } & \multicolumn{1}{|c|}{ Padrino } & \multicolumn{1}{|c|}{ Madrina } \\
\hline I784 & $\begin{array}{l}\text { María Paje } \\
\text { India }\end{array}$ & Petronila Paje & $\begin{array}{l}\text { Carlos Tello } \\
\text { Francisco Salfate }\end{array}$ & $\begin{array}{l}\text { María del } \\
\text { Carmen } \\
\text { J. Pinto }\end{array}$ \\
\hline 1785 & Dolores & Josefa & $\begin{array}{l}\text { Carlos Tello } \\
\text { Fernando Quiroz }\end{array}$ & $\begin{array}{l}\text { Josefa Hernández } \\
\text { María Bocanegra }\end{array}$ \\
\hline 1787 & $\begin{array}{l}\text { Alejo Moreno } \\
\text { Indio }\end{array}$ & $\begin{array}{l}\text { Mercedes } \\
\text { Moreno }\end{array}$ & $\begin{array}{l}\text { Carlos Tello } \\
\text { José Santis }\end{array}$ & $\begin{array}{l}\text { Josefa Barros } \\
\text { Ana Meneses }\end{array}$ \\
\hline & $\begin{array}{l}\text { Lestizo } \\
\text { Mereno }\end{array}$ & Juliana Moreno & $\begin{array}{l}\text { Carlos Tello } \\
\text { José Santos Quiroz }\end{array}$ & Rafaela Quiroz \\
\hline
\end{tabular}

Fuente: elaboración propia a partir de los registros de bautismo de la parroquia de San José y capilla de Chiñigue (AAS, AB, libros 4 y 6, I784-1802).

Los casos mencionados muestran la vigencia de la reciprocidad como mecanismo de fortalecimiento y ampliación de lazos con los caciques. La reciprocidad podía acrecentarse cuando los lazos familiares y rituales por compadrazgo exigían, de alguna forma, una retribución de obligaciones. Así, en palabras de Chamorro,

[...] las relaciones de familiaridad reflejan una gran red de contribuciones que permiten la supervivencia del modelo de reciprocidad. De manera directa se depende de familiares cercanos y lejanos, además del compadrazgo, de los cuales se espera cierta responsabilidad y la que genera ciertas obligaciones por parte de los participantes. (2I)

Los casos de las solteras y los solteros indígenas elegidos entre cinco y nueve ocasiones como madrinas y padrinos también son interesantes, ya que pueden relevar la posición social que tuvieron en sus comunidades y las influencias que algunos pudieron tener en sus linajes familiares de pertenencia (tabla 6). 
$\rightarrow$ TABLA 6

Madrinas y padrinos en condición de soltería, I780-I8Io

\begin{tabular}{|c|c|c|c|}
\hline Solteras & $\begin{array}{l}\text { Número de } \\
\text { madrinazgos }\end{array}$ & Solteros & $\begin{array}{l}\text { Número de } \\
\text { padrinazgos }\end{array}$ \\
\hline Catalina Soriano & $9(1780-1792)$ & Santiago Balcázar & $6(1780-1794)$ \\
\hline Josefa Canileu & $8(\mathrm{I} 782-\mathrm{I} 807)$ & José Jayba & $5(1786-1793)$ \\
\hline Micaela Astorga & $7(1790-1804)$ & Tomás Collipangue & $5(1796-1803)$ \\
\hline Martina Jorquera & $6(1794-1803)$ & & \\
\hline Cecilia Balcázar & $6(1780-1790)$ & & \\
\hline Catalina Jayba & $5(\mathrm{I} 78 \mathrm{I}-\mathrm{I} 788)$ & & \\
\hline Carmen Mesa & $5(1789-1803)$ & & \\
\hline María Teresa Caritoro & $5(1786-1792)$ & & \\
\hline
\end{tabular}

Fuente: elaboración propia a partir de los registros de bautismo de la parroquia de San José de Logroño y viceparroquia de Cuncumén (AAS, AB, libros 4-7, I780-I8IO).

Es importante resaltar la presencia de las madrinas. Si bien no tenemos fuentes que nos hablen de su vida material, ellas formaron parte de familias cuyos integrantes fueron caciques, como es el caso de las familias Soriano y Mesa, compartiendo entre iguales una misma vida social, religiosa y cultural, en comunidades y pueblos de indios con vivencias y experiencias semejantes, como penurias económicas o verse envueltos en la reducción de sus tierras por los hacendados colindantes con sus tierras. Aquello pudo posibilitar el que se estrecharan lazos de solidaridad y se ampliaran las perspectivas de sobrevivencia, si se escogían madrinas de semejante condición social y étnica. En algunas ocasiones, la predilección estuvo por las esposas, en desmedro de sus esposos, como se observa en la tabla 7 . 
$\rightarrow$ TABLA 7

Madrinazgos de esposas elegidas en reiteradas ocasiones, I780-I8Io

\begin{tabular}{|c|c|c|c|}
\hline Esposo & $\begin{array}{l}\text { Número de } \\
\text { ahijados }\end{array}$ & Esposa & $\begin{array}{l}\text { Número de } \\
\text { ahijados }\end{array}$ \\
\hline Don Tomás Soriano, Cacique & $5(1789-1791)$ & $\begin{array}{l}\text { Pascuala Escobar, } \\
\text { Española }\end{array}$ & IO (I780-1799) \\
\hline José Antonio Selada & $4(1783-1790)$ & Rafaela Mesa, India & $8(\mathrm{I} 78 \mathrm{I}-\mathrm{I} 790)$ \\
\hline Lorenzo Olivares & Sin registro & Basilia Rojas & $8(\mathrm{I} 796-\mathrm{I} 8 \circ 8)$ \\
\hline Juan Lesana & $2(1802,1806)$ & Santos Rojas & 7 (1792-1810) \\
\hline Cayetano Barrera & Sin registro & $\begin{array}{l}\text { Basilia Collipangue, } \\
\text { India }\end{array}$ & 7 (1793-I805) \\
\hline
\end{tabular}

Fuente: elaboración propia a partir de los registros de bautismo de la parroquia de San José de Logroño y viceparroquia de Cuncumén (AAS, AB, libros 4-7, I780-I8IO).

No se cuenta con documentación que trate sobre la vida material de las esposas, pero se han observado sus lazos familiares y los lazos sociales de compadrazgo, para determinar la influencia que pudieron tener entre sus pares sociales a la hora de ser escogidas como madrinas.

El caso de Pascuala Escobar es significativo. Esposa del cacique Tomás Soriano, fue escogida por familias populares en diez ocasiones para establecer madrinazgos. La influencia política de su esposo y el estatus en el pueblo de Pomaire pudo ser importante para escogerla, pero además se considera que Tomás Soriano no era muy querido por la comunidad de indígenas, ya que algunos se mostraban dubitativos de su condición de cacique y su calidad étnica, acusado de ser mulato (AHN, RA, Juicio que sigue Domingo Pomaire y otros contra Alonso Velásquez de Covarrubias por injurias y malos tratamientos, volumen II54, pieza I, Melipilla I773-I776, f. 2I). En esta perspectiva, pudo darse que las familias reconocieran la figura del cacique a través de su esposa y que actuaran estratégicamente en la captación de clientela, amén de apoyar la legitimidad del poder de su esposo.

También es relevante el caso de Rafaela Mesa, madrina en ocho oportunidades, que formó parte del extendido linaje Mesa, entre cuyos integrantes se cuenta a un cacique del pueblo de indios de Pomaire. En este sentido, las esposas de caciques como Pascuala Escobar y Rafaela Mesa muestran las jugadas estratégicas efectuadas, por las reiteradas oportunidades en que oficiaron 
como madrinas de bautismo, una práctica de la que tanto sus hijas como otras mujeres de la familia cacical también pudieron ser partícipes³.

En cuanto a Rafaela Mesa, fue casada con José Antonio Selada con quien tuvo seis hijos. Para padrinos de bautismo buscaron a miembros de la élite local de Melipilla. Así, cuando bautizaron a su hijo mayor, Miguel, la opción de padrino de bautizo fue Nolasco Eraso, quien mantuvo negocios con los comerciantes de la villa. El segundo hijo, llamado Esteban, tuvo por padrino a don Juan Toro, emparentado con la familia de comerciantes de los Piñeiro. También el cuarto hijo, José Manuel, tuvo de padrino a don Francisco Barba y como madrina a doña María del Carmen Peñalillo, hermana de doña Teresa Peñalillo, casada con Vicente Vargas, poseedor de la hacienda Melipilla (aAs, libros 4 y 5, Actas de bautismo de Miguel, Esteban y José Manuel, AB, I780, I782, I790, f. 297, s/f, 297, respectivamente, y AHN, NM, Inventario, tasación y partición de bienes de Vicente Vargas, vol. 28, Melipilla I8II, f. 35).

En este sentido, las relaciones familiares y las relaciones por compadrazgos forjadas por la familia Selada Mesa pudieron representar para las familias indígenas del valle un capital social inherente, como el prestigio de estar relacionadas con familias importantes y la capacidad que pudo tener la misma familia Selada Mesa para movilizar solidaridades y mediaciones de ayuda para sus compadres y ahijados con las familias de la élite local emparentadas con ellos.

Resulta interesante observar las relaciones que entablaron los indígenas con personas de diferente estatus social, personas consideradas por ellas mismas o por personas externas en aparente grado de desigualdad respecto a las otras, ya fuera de tipo económico, político o social, como señala Morrone (i9). Justamente, Alison Spedding sostiene que el compadrazgo permitió la formación de lazos duraderos entre personas de diferentes clases sociales y comunidades de origen, "siendo deseable elegir un padrino económicamente solvente o bien un compadre que facilite el intercambio de distintos pisos ecológicos" (II7). De igual forma, sigue siendo importante el compromiso que media en este tipo de relación, permitiendo fortalecer relaciones dadas con anterioridad, como el trabajo o la

3 La importancia de la mujer también la vemos en otros contextos hispanoamericanos, como fue el cuzqueño. Así, Ariel Morrone releva el valor de las mujeres cacicales de la élite cuzqueña en el establecimiento de alianzas con las familias de las comunidades, pero también incorporando y reclutando a forasteros a la trama social del pueblo. Para esto, operaron a través del compadrazgo remitiendo grados de autonomía con respecto a padres, hijos, hermanos y esposos (29). 
vecindad, pero también conquistar y consolidar uniones político-económicas y establecer lazos clientelares.

\section{Conclusiones}

Las relaciones de compadrazgo se configuraron tendencialmente asimétricas, en diversas escalas, entre los indígenas del valle de Melipilla cuando establecieron relaciones horizontales. La inclinación hacia determinados sujetos para oficiar de padrinos se relacionó con una situación económica más favorable respecto a sus pares sociales, como también aquellos que estuvieran relacionados con familias importantes de la villa, como comerciantes o agricultores con mejor pasar económico y alianzas sociopolíticas ventajosas. Así, se observó que hubo preferencia por los caciques de los pueblos de indígenas, en los que resalta su posición jerárquica dentro de la comunidad. A estos se ha atribuido una posición de intermediarios entre la comunidad y las autoridades coloniales, pudiendo interceder en negociaciones o conciliaciones entre las partes; por ejemplo, los conflictos relacionados con el acceso a las tierras (ventas y arriendos). En definitiva, las opciones de los padres se condijeron a las expectativas futuras extrapoladas a las vías materiales, en el sentido de adquisición de bienes y riqueza que pudieron recibir mediante el compadrazgo.

Es necesario señalar también que en las relaciones de compadrazgo no siempre las fidelidades y las redes de protección se concretaron a través de beneficios tangibles, como bien seńala Eliane Cristina Lopes Soares:

[...] la invisibilización de las donaciones, no significó que los favores no existieran, principalmente porque las expectativas de los padres pudo estar en otros niveles de intereses, tales como beneficios, empleos, favorecimientos políticos o el status de ser compadre de una autoridad. (89)

Lo anterior puede extrapolarse al caso de las madrinas. Estas, si bien no ostentaron grandes patrimonios materiales, su capital se asoció al social y a los vínculos familiares que sustentaban su estatus y prestigio. Así, las madrinas elegidas en reiteradas ocasiones, como las esposas legítimas, las hijas y tal vez las mujeres secundarias emparentadas con los linajes cacicales, representaron para sus grupos familiares poder fortalecer redes personales y sociales, estrechando vínculos familiares cacicales con otros miembros de los pueblos de 
indios (mestizos, mulatos), como también la incorporación de "forasteros" y arrendatarios de tierras.

Por consiguiente, los vínculos por compadrazgo entre sujetos populares nos hablan de las relaciones de poder, con base en las relaciones que escogieron los sujetos, siendo más importante diversificar los lazos con el conjunto de la población que reafirmar lazos familiares, en los casos en que sujetos específicos ostentaban prestigio socioeconómico y político. En sí, las relaciones de compadrazgo establecidas por la sociedad de Melipilla dejan al descubierto el tejido social de la época de fines del siglo xvin y revelan la complejidad de la trama de relaciones sociales que se desarrollaron en la vida rural melipillana, pero más importante aún es que permiten explicar la estructura de poder en las que estuvieron insertos los indígenas del valle central de Chile.

\section{$\infty$ \\ $\begin{array}{llllllllllll}\text { B I } & B & L & I & \mathbf{O} & G & \mathbf{R} & \mathbf{A} & \mathbf{F} & \mathbf{I} & \mathbf{A}\end{array}$}

\section{F U E N T E S P R I M A R I A S}

\section{A. Archivos}

Archivo Histórico Nacional de Chile, Santiago, Chile (AHN).

Fondo Notarios de Melipilla (NM), vols. 7, IO, II, I4, 26, 28.

Fondo Capitania General (CG), vols. I44, 512, 661.

Fondo Real Audiencia (RA), vol. 2191-pieza 7, II54-pieza I.

Fondo Judicial de Melipilla (JM), leg. 4 - pieza 8, 6 - pieza 19.

Fondo Claudio Gay (FCG), vol. 38, pieza 6, 1794-1798.

Archivo Arzobispado de Santiago, Santiago de Chile, Chile (aAs).

Fondo Parroquial San José de Melipilla (PJM).

Actas de bautismo $(A B)$, libros 4 a 7, 1780-1810.

Actas de Matrimonio $(A M)$, libros 2 a 4, $1780-1816$.

\section{FUENTESSECUNDARIAS}

Borde, Jean y Mario Góngora. Evolución de la propiedad rural en el valle del Puangue. Santiago de Chile: Universitaria, 1956. 
Chamorro Rosero, Mauricio. "Compadrazgo y reciprocidad en los Andes colombianos: el caso de Gualmatán (Nariño). Colombia”. Diálogo Andino, n. 51, 2016, pp. 17-29. https://doi.org/10.4067/s0719-26812016000300017

Contreras, Jesús. "El compadrazgo y los cambios de estructura de poder local en Chinchero (Perú)”. Boletín Americanista, n. 29, 1979, pp. 5-29.

De Ramón, Armando. "La sociedad española de Santiago de Chile entre i581 y i596 (estudio de grupos)". Historia, n. ${ }^{\circ}$, 1965, pp. 191-228.

Elias, Norbert. La sociedad de los individuos. Ensayos. Barcelona: Ediciones Península, 1990.

Góngora, Mario. Origen de los “inquilinos” de Chile central. Santiago de Chile: Universidad de Chile, i960.

Gudeman, Stephen. "Spiritual Relationships and Selecting a Godparent”. Man, vol. Io, n. 2, 1975, pp. 22 I-237. https://doi.org/10.2307/2800496

Ibarra, Antonio y Guillermina Del Valle Pavón. "Introducción, las redes sociales como explicación del pasado". Redes sociales e instituciones comerciales en el imperio español, siglos XVII a XIX, coordinado por Antonio Ibarra y Guillermina del Valle. México D. F.: UNAM/Instituto Dr. José María Mora, 2007, pp. I-I8.

Imolesi, María Elena. "Haciendo y deshaciendo parientes en los Andes coloniales. Algunas reflexiones en torno al parentesco espiritual”. III Simposio Internacional sobre Religiosidad, Cultura y Poder. Ciudad Autónoma de Buenos Aires, 20ı, pp. I-I 4.

León, Leonardo. "Rebeldía, disputas y conflictos en el 'pueblo de indios' de Pomaire (Chile Central), I790-1811)”. Cuadernos de Historia, vol. 35, 2011, pp. 93-134. https://doi. org/10.4067/s0719-12432011000200004

Lima da Silva, Cristiano. "Senhores e também padrinhos: relações de compadrio e as alforrias na pia batismal em São João del Rei (I750-1850)”. Anais do XXVI Simpósio Nacional de História, São Paulo, 201 i, pp. I-IO.

Lopes Soares, Eliane Cristina. Família, compadrio e relaçóes de poder no Marajó. S. XVIII $X I X$. Tesis doctoral en Historia, Pontificia Universidad Católica de São Paulo, 20 ıo.

Lorandi, Ana María. "Identidades ambiguas: Movilidad social y conflictos en los Andes, siglo Xviı". Anuario de Estudios Americanos, vol. 57, n. ${ }^{\circ}$ I, 2000 , pp. III-I35. https:// doi.org/10.3989/aeamer.2000.v57.ir.26I

Montes del Castillo, Ángel. Simbolismo y poder. Un estudio antropológico sobre el compadrazgo $y$ priostrazgo en una comunidad andina. Barcelona: Anthropos, 1989.

Morrone, Ariel. "Mujeres cacicales en el tablero colonial. Familia, parentesco y poder étnico en el lago Titicaca (I580-I750)”. Andes. Antropologia e Historia, vol. I, n. ${ }^{\circ} 29,2018$, pp. I-3I. 
Ojeda, Ema. Estudio de los libros parroquiales de Melipilla desde los años I7Io a I760. Memoria de prueba de Historia, Geografía y Ciencias Sociales, Universidad Católica de Valparaíso, i96r.

Requena Santos, Félix. "Orígenes sociales del análisis de redes”. Análisis de redes sociales. Origenes, teorias y aplicaciones, editado por Félix Requena. Madrid: Centro de Investigaciones sociológicas y Siglo XXI, 2003.

Spedding, Alison. "Contra-afinidad: algunos comentarios sobre el compadrazgo andino". Gente de carne y hueso. Las tramas de parentesco en los Andes, editado por Denise Arnold. La Paz: CIASE-ILCA, I998, pp. II3-I37. 